\title{
PUT \& CALL OPTION SAHAM LOKAL MENGGUNAKAN BLACK-SCHOLES MODEL DAN MATLAB PACKAGES
}

\author{
Alpi Mahisha Nugraha \\ Teknik Informatika, Universitas Indraprasta PGRI \\ Jl. Raya Tengah No. 80, Kel. Gedong, Kec. Pasar Rebo, Jakarta Timur, DKI Jakarta \\ alpi.mahisha@gmail.com
}

\begin{abstract}
ABSTRAK
Menganalisis harga Put \& Call Option Asia merupakan salah satu hal yang saat ini masih menjadi topik menarik untuk ditelaah. Penggunaan beberapa pendekatan seperti Monte Carlo, Lattice Multinominal dan lainnya masih belum dapat menduga pergerakan dari karakter harga Put \& Call Option di Asia. Hal ini dapat disebabkan karena pergerakan saham yang sangat fluktuatif dan dipengeruhi oleh banyak hal. Pada penelitian ini menggunakan model Black-Scholes dan dibantu menggunakan MATLAB packages untuk mengetahui sensitivitas harga harga Put \& Call Option Asia (saham TLKM dan BTPS) terhadap kenaikan suku bunga, bentuk kontrak, dan elastisitas harga saham. Meskipun hasil perhitungan menggunakan MATLAB Packages yang diperoleh tidak cukup presisi, namun memiliki pola perilaku yang sama dengan perhitungan model BlackScholes terutama pada pengaruh perubahan suku bunga dan jenis kontrak.
\end{abstract}

Kata Kunci: Put \& Call Option, Pemodelan Black-Scholes, MATLAB Packages

\begin{abstract}
Put \& Call Option Asia is one of interesting topic to be studied currently. Some approximations such as Monte Carlo, Lattice Multinominal and the others cannot predict the movement of character of Put \& Call Option price in Asia, this phenomenon can be caused by the highly volatile stock movement which is depend by many things. In this research, we using the Black-Scholes model and will be compared by using MATLAB packages to determine the price sensitivity of the Asian Put \& Call Option price (TLKM and BTPS) to the increase in interest rates, the form of contracts, and the elasticity of stock prices. Although the results haven't enough precision with MATLAB Packages, but have the same character pattern with Black-Scholes model, especially on the effect of increase in interest rates and form of contracts.
\end{abstract}

Key Word: Put \& Call Option, Black-Scholes Model, MATLAB Packages

\section{PENDAHULUAN}

Pendekatan matematika dan fisika teori bukanlah hal yang baru dalam menganalisis fenomena ekonomi. Sejak beberapa dekade lalu, fenomena ekonomi seperti pergerakan saham dan semua perangkatnya menggunakan persamaan matematik (Junghenn, 2019). Bahkan beberapa ilmuwan fisika berani "menyelam" di bidang ekonomi dan menjadi puncaknya pada tahun 2003 peraih nobel ekonomi yang memiliki background ahli ilmu hitung seperti fisika terapan.

Saham adalah sertifikat yang menunjukan bukti kepemilikan suatu perusahaan, kepemilikannya membuat pemilik mempunyai hak atas penghasilan dan aktiva perusahaan. Karena keseimbangan permintaan dan penawaran yang dipengeruhi oleh banyak faktor baik internal perusahaan atau eksternal perusahaan membuat harga saham dalam indeks berubah dari waktu ke waktu atau bersifat derivatif.

Hal ini menyebabkan para investor harus berfikir matang saat melakukan pembelian saham (Sari et al., 2017), Derivatif dalam ekonomi beranalogi sama dengan istilah diferensial dalam matematika yaitu turunan dari suatu fungsi (Janková, 2018). Derivatif dalam ekonomi merupakan surat berharga yang nilainya bergantung pada surat berharga tersebut. Dengan kata lain derivatif merupakan surat perjanjian yang memiliki nilai resiko, untuk mengurangi resiko terebut diperlukan proses hedging (nilai lindung). Nilai lindung inilah yang disebut dengan Option atau opsi.

Option ada dua macam yaitu put option atau opsi jual dan call option atau opsi beli. Put option dan call option adalah suatu hak untuk menjual dan membeli sebuah asset pada harga kesepakatan (strike price) dalam jangka 
waktu tertentu yang telah disepakati (Putri Rizka, dkk, 2014), baik pada akhir masa jatuh tempo (Opsi Eropa) ataupun di antara tenggang waktu masa sebelum jatuh tempo (Opsi Amerika), ataupun pada waktu keduanya (Opsi Barier) seperti harga opsi Asia (Lessy, 2013).

Pergerakan put \& call option Asia meru-pakan pergerakan derivatif yang begotu fluktuatif, beberapa pendekatan seperti monte carlo (Amami Pramuditya, 2017), binomial dan trinomial (Meliyani et al., 2016), metode lattice multinominal (Nur Roza Fitriyana dan Deni Saepudin, 2015) dengan asumsi pergerakan saham yang bersifak eksponensial. Sayangnya, pendekatan metode ini dirasa masih belum cukup dapat menduga pergerakan dari harga opsi Asia yang begitu fluktuatif.

Terdapat juga penelitian dalam menganalisis harga opsi Asia dengan pendekatan penggunaan rata-rata aritmatika dengan aproksimasi curran (Harwella, 2014), namun sayangnya karena harga opsi Asia tidak bersifat lognormal sehingga pendekatannya kurang memuaskan.

Pada penelitian ini, untuk melihat sensitivitas harga opsi Asia akan dilakukan perbandingan antara perhitungan analitik menggunakan model black-scholes terhadap MATLAB packages yang dapat menghitung harga opsi dengan sensitivitas terhadap kenaikan suku bunga, jenis kontrak, dan elastisitas harga saham itu sendiri.

Pergerakan harga opsi yang akan ditelaah pada penelitian ini adalah harga saham di Asia yaitu TLKM (PT Telekomunikasi Indonesia) dan BTPS (PT BTPN Syariah). Pertimbangan kedua harga saham ini dikarenakan TLKM dan BTPS merupakan saham yang tinggi peminat ketika Indeks Harga Saham Gabungan (IHSG) menurun.

\section{METODE PENELITIAN}

Penelitian dilakukan dengan menghitung harga opsi TLKM dan BTPS pada 11 Agustus 2021 sampai dengan 11 November 2021 yang terdiri dari 14 minggu. Perhitungan menggunakan model Black-scholes (Black \& Scholes, 1973) dengan persamaan sebagai berikut:

$$
\begin{aligned}
& C=S e^{-q t} N\left(d_{1}\right)-K e^{-r t} N\left(d_{2}\right) \\
& P=K e^{-r t} N\left(-d_{2}\right)-S e^{-q t} N\left(-d_{1}\right) \\
& \text { dengan } \\
& d_{1}=\frac{\ln \left(\frac{S}{K}\right)+t\left(r-q+\frac{\sigma^{2}}{2}\right)}{\sigma \sqrt{t}} \\
& \text { dan } \\
& d_{2}=d_{1}-\sigma \sqrt{t} \\
& \text { Keterangan: } \\
& C=\text { Call option } \\
& P=\text { Put option } \\
& S=\text { harga saham (Strike) } \\
& K=\text { harga kesepakatan } \\
& r=\text { suku bunga bebas resiko } \\
& \sigma=\text { volatilitas } \\
& q=\text { deviden }
\end{aligned}
$$

Hasil dari perhitungan ini dianalisis berupa perbandingan dengan perhitungan menggunakan MATLAB packages yang dapat melihat sensitivitas harga opsi terhadap suku bunga, jenis kontrak dan elastisitas harga. Penggunaan MATLAB packages dilakukan dengan sintak MATLAB berupa:

1. Model Black-Scholes dengan modifikasi kontrak dengan sintak "[Call, Put $]=$ blkprice(Price, Strike, Rate, Time, Volatility)"

2. Model Black-Scholes yang dimodifikasi sensitif pada perubahan kenaikan suku bunga "[CallRho, PutRho]= blsrho(Price, Strike, Rate, Time, Volatility,Yield)"

3. Model Black-Scholes yang dimodifikasi sensitif pada elastisitas harga saham atau kepekaan konsumen pada perubahan harga saham, sintak yang digunakan "[CallEl, PutEl] = blslambda(Price, Strike, Rate, Time, Volatility,Yield)"

Perhitungan akan terdiri dari empat buah analisis kurva harga opsi (put \& call option) TLKM dan BTPS yang terdiri dari perhitungan analitik dengan menggunakan persamaan (1) dan persamaan (2) dengan suku bunga $3.5 \%$ sesuai dengan yang diterapkan pemerintah pada bulan Agustus 2021 sampai dengan November 2021, kemudian tiga analisi perhitungan menggunakan MATLAB packages. 


\section{HASIL DAN PEMBAHASAN}

Harga opsi di Asia bersifat fluktuatif karena banyaknya negara yang masih berkembang sehingga kebijakan internal perusahaan dan faktor eksternal seperti kebijakan pemerintah dalam menentukan suku bunga dan lainnya menjadi faktor penentu dari harga saham itu sendiri. Disisi lain model black-scholes juga memiliki batasan kondisi yang belum tentu sesuai dengan kondisi saham lokal (Janková, 2018).

Saham TLKM (PT Telekomunikasi Indonesia) yang bekerja di bidang komunikasi dan BTPS (PT Bank BTPN Syriah) yang bekerja di bidang keuangan merupakan PT yang tergabung dalam IHSG, kedua saham ini masih memiliki peminat tinggi meskipun harga saham IHSG menurun, yang artinya perusahaan ini cukup stabil perkembangannya sehingga banyak diminati oleh para investor.

Karakteristik dan sensitivitas harga put \& call option dapat dilihat pada Gambar 1 dan Gambar 2. Harga put option di BTPS pada awal minggu di bulan Agustus 2021 memiliki sinsitivitas yang tinggi terhadap nilai suku bunga dan jenis kontrak opsi yang disepakati. Namun kembali tidak sensitif pada pekan akhir di bulan September sampai dengan bulan November. Sedangkan untuk harga call option BTPS, kurva analitik hampir mirip karakteristiknya dengan kurva yang dipengaruhi oleh suku bunga dan jenis kontrak untuk sepanjang waktu di bulan Agustus sampai dengan bulan November. Hal ini menunjukkan bahwa call option BTPS memiliki sensitivitas yang tinggi terhadap kedua hal tersebut.

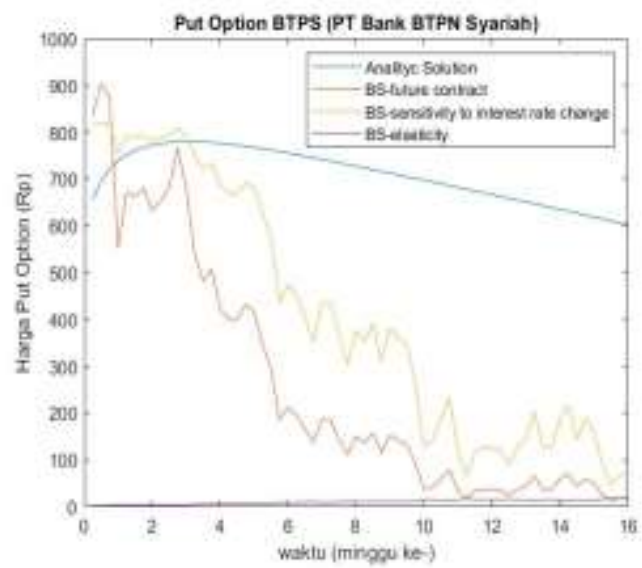

Gambar 1. Harga Put Option BTPS (11 Agustus '21-11 November'21)

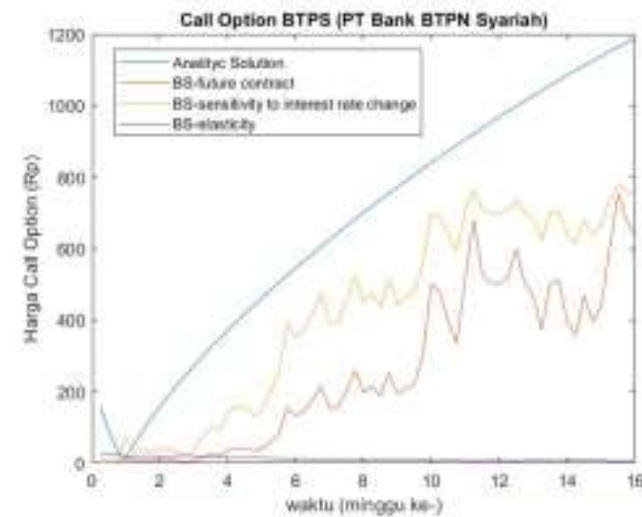

Gambar 2. Harga Call Option BTPS

(11 Agustus '21-11 November'21)

Berbeda dengan sensitivitasnya terhadap nilai suku bunga dan jenis kontrak. Harga opsi BTPS baik put option ataupun call option tidak ada keterkaitannya terhadap elastisitas harga yang ditunjukkan dengan sensitivitas yang rendah. Dari Gambar 1 dan Gambar 2 dapat terlihat bahwa nilai harga call option meningkat dan harga put option menurun pada bulan September 2021 dan bulan November 2021 sehingga banyaknya transaksi pembelian pada waktu tersebut.

Harga put \& call option TLKM memiliki karakteristik yang cukup berbeda dengan harga opsi BTPS yang dapat dilihat pada Gambar 3 dan Gambar 4. Namun untuk harga put option TLKM sangat sensitif terhadap jenis kontrak yang dilakukan sehingga kurvanya menempel dengan kurva analitik. Sedangkan untuk sensitivitas terhadap nilai suku bunga tidak terlalu dekat namun memiliki tren yang sama dengan kurva analitik. Sensitivitas terhadap elastisitas harga saham cukup tinggi di bulan Oktober 2021 dan November 2021.

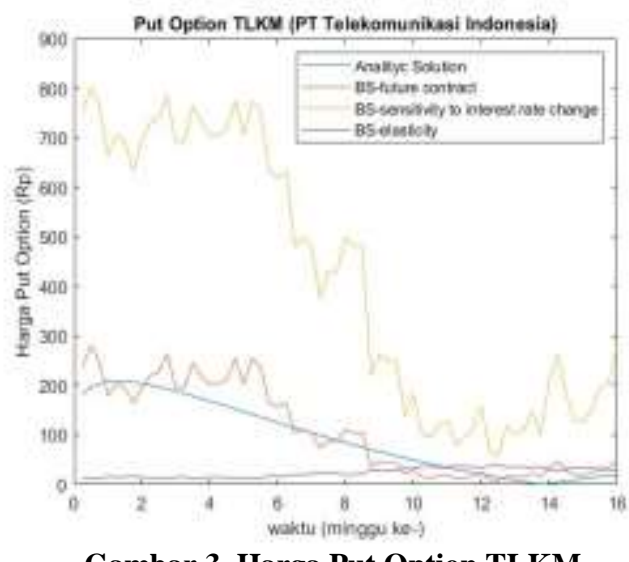

Gambar 3. Harga Put Option TLKM (11 Agustus '21-11 November'21) 


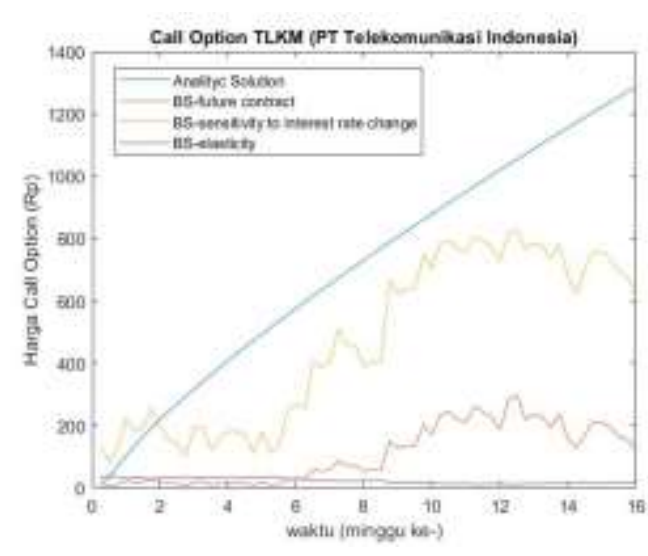

Gambar 4. Harga Call Option TLKM

(11 Agustus '21-11 November'21)

Sama halnya dengan harga call option BTPS, call option TLKM sensitif terhadap nilai suku bunga dan jenis kontrak dan sensitifitas yang rendah terhadap elastisitas harga. Namun berbeda dengan harga put option TLKM lebih sensitif terhadap nilai suku bunga alih-alih sensitivitas terhadap jenis kontrak.

Karakteristik harga put \& call option pada periode Agustus dan November cukup baik untuk melakukan pembelian karena kurva call option yang terus meningkat dan put option yang menurun. Analisis seperti ini yang dapat dilakukan sehingga investor aman untuk membeli saham dari perusahaan tersebut.

\section{SIMPULAN DAN SARAN}

Harga put \& call option BTPS memiliki sensitivitas yang cukup tinggi terhadap nilai suku bunga dan jenis kontrak terutama pada bulan September 2021 sampai dengan November 2021, namun memiliki sensitivitas yang rendah terhadap elastisitas harga saham. Sedangkan harga put option TLKM memiliki sensitivitas yang sangat tinggi terhadap jenis kontrak meskipun terhadap nilai suku bunga memiliki tren yang sama. Senstivitas terhadap elastisitas harga cukup berpengaruh pada harga put option TLKM di bulan Oktober 2021 dan November 2021. Karakteristik harga call option TLKM cukup berbeda dengan harga put option TLKM dikarenakan lebih sensitif terhadap nilai suku bunga dibandingkan dengan jenis kontrak. Masih munculnya perbedaan dengan analitik menunjukkan bahwa model Black-Scholes memang memerlukan kondisi yang sesuai dengan asumsi pemodelan tersebut yang masih belum cocok dengan harga opsi Asia. Meskipun TLKM dan BTPS cukup sensitif terhadap nilai suku bunga dan jenis kontrak maka diperlukan modifikasi lebih lanjut terhadap pemodelan Black-Scholes dalam menelaah harga opsi Asia.

\section{DAFTAR PUSTAKA}

Amami Pramuditya, S. (2017). Penentuan Harga Opsi Asia dengan Metode Monte Carlo. Jurnal Matematika "MANTIK," 03(01), 46-50.

https://doi.org/https://doi.org/10.15642/m antik.2017.3.1.46-50

Black, F., \& Scholes, M. (1973). The pricing of options and corporate. Chicago Journal, $81(3)$, 637-654. http://www.jstor.org/stable/1831029

Harwella, S. (2014). Penggunaan Rata-rata Aritmatika dengan Aproksimasi Curran dalam Menentukan Harga Opsi Asia. Jurnal Matematika UNAND, 3(4), 70-77.

Janková, Z. (2018). Drawbacks and Limitations of Black-Scholes Model for Options Pricing. Journal of Financial Studies and Research, 2018, 1-7. https://doi.org/10.5171/2018.79814

Junghenn, H. D. (2019). An Introduction to Financial Mathematics. An Introduction to Financial Mathematics. https://doi.org/10.1201/9780429263934

Lessy, D. (2013). Simulasi Monte Carlo dalam Penentuan Harga Opsi Barrier. Jurnal Matematika Dan Pembelajarannya, 2(2), 20-28.

Meliyani, R., Nugrahani, E. H., \& Lesmana, D. C. (2016). Penentuan Harga Opsi Call Window Reset menggunakan Metode Binomial Tree dan 2 Metode Binomial Tree dan Trinomial Tree. JMA, 15(2), 23.

Nur Roza Fitriyana, Deni Saepudin, I. P. (2015). Penentuan Harga Opsi (Call) Asia Menggunakan Metode Lattice Multinominal. E-Proceeding of Engineering, 2(3), 7976-7986.

Putri Rizka Atika Yusli, Riri Lestari, Y. A. (2014). Penerapan Simulasi Monte Carlo dalam Penentuan Harga Opsi Asia. Jurnal Matematika UNAND, VI(3), 40-46.

Sari, L. K., Achsani, N. A., \& Sartono, B. (2017). Pemodelan Volatilitas Return Saham: Studi Kasus Pasar Saham Asia Modelling Volatility of Return Stock Index: Evidence from Asian Countries. Jurnal Ekonomi Dan Pembangunan Indonesia, 18(1), 35-52. 